\title{
Nilai Tambah Pada Agroindustri Dodol Tomat (Studi Kasus Pada Usaha Kelompok Wanita Tani Mentari Desa Genteng, Kecamatan Sukasari, Kabupaten Sumedang)
}

\section{Added Value Of Agroindustry Dodol Tomat (Case Study of Agroindustry Dodol Tomat in Genteng Village, Sukasari Sub-District, Sumedang City)}

\author{
Izati Rahmi $^{{ }^{*},}$, Lucyana Trimo ${ }^{1}$ \\ ${ }^{1}$ Program Studi Agribisnis Universitas Padjajaran \\ *E-mail : izatirahmi21@gmail.com
}

\begin{abstract}
Genteng Village having its natural resources agricultural abundant, which is dominated by the various types plants horticulture one of them commodities are tomatoes. Agroindustry Dodol Tomat is one and only industry that processes tomato processing into refined products since 2017 by KWT Mentari. The purpose of this research is to describe the performance of agro-processing industry of dodol tomat, and to know added value obtained from processing of tomatoes until into become dodol tomat. This research uses qualitative design with case study technique. The data analysis methods that being used Hayami's added value analysis method. This research result indicates that the value added is received on the business of dodol tomat amounting to Rp 11.340 per kilogram with a ratio of added value to the average output value of $37,8 \%$ per production process.
\end{abstract}

Keywords: Tomatoes, Value Added, Performance of Agroindustry.

Disubmit : 20 Agustus 2019, Diterima: 6 September 2019, Disetujui : 15 Oktober 2019

\section{PENDAHULUAN}

Desa Genteng merupakan desa yang terletak di Kecamatan Sukasari, Kabupaten Sumedang, Provinsi Jawa Barat. Desa Genteng merupakan daerah pegunungan dan perbukitan, termasuk dalam kategori dataran tinggi dengan ketinggian tempat 800-1200 mdpl dengan suhu lingkungan 18-22 $\mathrm{C}$ (BPS Kabupaten Sumedang, 2018). Letak yang strategis dan sumber daya alam yang melimpah menjadikan Desa Genteng memiliki potensi dalam mengembangkan usaha pertanian, sehingga sektor pertanian merupakan sektor yang penting dalam pembangunan perekonomian masyarakat Desa Genteng. Berikut data potensi pertanian hortikultura Desa Genteng dirinci menurut jumlah produksi pada Tabel 1.

Tabel 1. Produksi Komoditas Hortikultura Desa Genteng Kecamatan Sukasari Tahun 2017 dan 2018.

\begin{tabular}{clcc}
\hline \multirow{2}{*}{ No } & \multirow{2}{*}{ Komoditas } & \multicolumn{2}{c}{ Produksi (kw) } \\
\cline { 3 - 4 } & & Tahun 2017 & Tahun 2018 \\
\hline 1 & Bawang Merah & 214 & 90 \\
2 & Kentang & 14.984 & 14.122 \\
3 & Kubis & 20.918 & 21.467 \\
4 & Cabe Rawit & 1.146 & 1.981 \\
$\mathbf{5}$ & Tomat & $\mathbf{9 . 7 3 7}$ & $\mathbf{6 . 9 2 6}$ \\
\hline
\end{tabular}




\begin{tabular}{clcc}
\hline 6 & Buncis & 615 & 578 \\
7 & Ketimun & 697 & 346 \\
8 & Bawang Daun & 5.239 & 3.701 \\
9 & Kembang Kol & - & - \\
10 & Petsai & 3.044 & 1.971 \\
11 & Terung & - & 255 \\
12 & Kacang Panjang & 892 & 970 \\
13 & Kacang Merah & 3.237 & 331 \\
14 & Cabe Merah & 8.889 & 1.146 \\
15 & Jamur & 2.523 & - \\
16 & Cabe Keriting & 7.561 & 6.661 \\
17 & Labu Siam & 647 & 530 \\
18 & Wortel & - & - \\
\hline
\end{tabular}

Sumber: BPS Kecamatan Sukasari tahun 2017 dan 2018

Berdasarkan data Tabel 1. diatas menunjukkan bahwa potensi pertanian hortikultura terbesar di Desa Genteng yaitu komoditas kentang, kemudian disusul dengan komoditas kubis dan tomat di urutan kedua dan ketiga. Dari ketiga komoditas tersebut, tomat merupakan salah satu komoditas yang menjadi mata pencaharian banyak petani di Desa Genteng. Namun, banyaknya jumlah produksi tomat di Desa Genteng belum sepenuhnya memberikan dampak kesejahteraan bagi perekonomian petani tomat. Berdasarkan wawancara bersama salah seorang petani tomat di Desa Genteng, tingginya jumlah produksi tomat disaat musim panen raya menyebabkan para petani terpaksa menjual tomat dengan harga murah untuk menghindari kerugian akibat kerusakan, harga jual tomat terendah yaitu mencapai sebesar Rp. 800 per kilogram. Apabila ketersediaan tomat melebihi dari jumlah permintaan, maka akan berakibat pada segi harga yang relatif akan menurun sesuai dengan hukum permintaan (Dinar dan Marina, 2018).

Permasalahan harga ini juga disebabkan karena panen serempak yang tak diimbangi dengan meningkatnya permintaan membuat harga komoditas tomat jatuh tajam, sehingga banyak tomat yang terbuang sia-sia bahkan petani memilih untuk membagikan tomat tersebut secara gratis terkadang membiarkan hasil panen tomat membusuk. Selain itu, tomat juga mempunyai karakter yang mudah rusak, umur simpan relatif pendek, sehingga dapat menyebabkan penurunan kualitas dan nilai ekonomi komoditas tomat tersebut (Purwadi et al, 2007).

Salah satu cara untuk menjaga nilai dan harga yang fluktuatif dari komoditas tomat adalah dengan menciptakan produk olahan yang bernilai tambah. Nilai Tambah (value added) adalah pertambahan nilai suatu komoditas karena mengalami proses pengolahan, pengangkutan ataupun penyimpanan dalam suatu produksi (Ruauw, 2015). Menurut Dewi, et al (2015) usaha pengolahan yang berbahan dasar komoditas pertanian mempunyai posisi penting yaitu sebagai jembatan untuk meningkatkan nilai tambah komoditas pertanian serta dapat memberikan tambahan pendapatan bagi masyarakat. Untuk menjaga stabilitas harga tomat, Dirjen Hortikultura Kementan mendorong agar ada diversifikasi produk tomat yang salah satunya adalah membuat produk olahan tomat seperti pasta, saus, manisan, dodol, hingga diolah menjadi tomat kurma atau torakur.

Akibat dari melimpahnya produksi tomat dengan harga murah menjadikan masyarakat Desa Genteng berusaha untuk menghasilkan level produk yang lebih tinggi dari sekedar komoditas (raw material). Berangkat dari hal tersebut, KWT Mentari yang merupakan binaan ogranisasi IAAS International Association of Students in Agricultural and Related Sciences (IAAS) LC Unpad di Desa Genteng, termotivasi dan memiliki inisiatif untuk melakukan penciptaan nilai tambah pada komoditas tomat yang memiliki permasalahan dalam harga jual dan pemasaran. KWT Mentari memiliki ide untuk mengolah tomat menjadi produk olahan dodol tomat. Pemilihan dodol tomat oleh KWT Mentari sebagai produk diversifikasi olahan tomat karena proses pembuatan yang mudah dan dapat dilakukan tanpa menggunakan bantuan alat 
atau teknologi yang canggih. Hal mendorong KWT Mentari untuk membuat olahan dodol tomat antara lain yaitu tersedianya bahan baku tomat dengan harga murah, keinginan untuk menambah penghasilan, dan usaha pengolahan tersebut dapat menciptakan lapangan pekerjaan bagi anggota KWT Mentari.

Konsep didirikannya agroindustri pengolahan dodol tomat ini adalah untuk memanfaatkan buah sortiran yang memiliki kualitas off grade disaat harga tomat murah. Agroindustri sebagai penarik pembangunan sektor pertanian diharapkan mampu berperan dalam menciptakan pasar baru bagi hasil-hasil pertanian melalui berbagai produk olahannya (Supriyati dan suryani 2016). Pengembangan usaha agroindustri pembentuk nilai tambah di perdesaan adalah upaya akumulasi nilai tambah berbasis lokal yang dapat meningkatkan pendapatan langsung bagi pengusaha dan petani atau tidak langsung bagi masyarakat desa secara umum (Bantacut, 2013). Oleh karena itu, melalui kegiatan pengolahan, diharapkan dapat meningkatkan nilai tambah (added value) bagi komoditas tomat yang dibudidayakan petani di Desa Genteng dan sebagai penopang pengahasilan masyarakat Desa Genteng khususnya petani tomat dan anggota KWT Mentari. Berdasarkan uraian diatas, maka peneliti melakukan penelitian terkait nilai tambah untuk meninjau penambahan nilai (added value) dari aktivitas pengolahan komoditas tomat di Desa Genteng.

\section{METODE PENELITIAN}

Penelitian ini dilaksanakan di Desa Genteng, Kecamatan Sukasari, Kabupaten Sumedang yang merupakan lokasi agroindustri dodol tomat KWT Mentari. Penentuan daerah penelitian dilakukan secara sengaja (purposive method) dengan pertimbangan karena Desa Genteng merupakan desa binaan organisasi IAAS LC Unpad melaui progam bina desa "Village Concept Project" bersama Kelompok Wanita Tani Mentari dan Desa Genteng merupakan satu-satunya desa mengolah komoditas tomat menjadi produk inovasi berbahan baku tomat.

Desain penelitian yang digunakan untuk penelitian ini adalah desain kualitatif, dan teknik penelitian yang digunakan adalah studi kasus (case study). Teknik studi kasus bertujuan untuk mengembangkan metode kerja paling efisien, sehingga peneliti mengadakan telah secara mendalam, kesimpulan hanya berlaku dan terbatas pada kasus tertentu (Iskandar, 2009).

Sumber data pada penelitian ini berupa data primer dan data sekunder. Data primer adalah data yang diperoleh langsung melalui wawancara dari pelaku usaha agroindustri dodol tomat sebagai informan kunci dan serta pihak-pihak yang terkait sebagai informan pendukung dengan menggunakan daftar pertanyaan yang sudah disiapkan sebelumnya. Sedangkan data sekunder merupakan data yang diperoleh dari instansi yang terkait (BPS, Dinas Pertanian, beserta instansi terkait lainya) dan berbagai media cetak dan media online beserta dari berbagai buku dan literatur yang berkaitan dengan penelitian ini.

Adapun analisis data yang digunakan pada penelitian ini yaitu analisis nilai tambah dengan menggunakan metode hayami. Menurut (Hayami (1987), nilai tambah (value added) adalah pertambahan nilai suatu komoditas karena mengalami proses pengolahan, pengangkutan ataupun penyimpanan dalam suatu produksi. Menurut (Hayami (1987) tujuan dari analisis nilai tambah adalah untuk menaksir balas jasa yang diterima oleh tenaga kerja langsung dan pengelola. mendapatkan perlakuan. Berikut tabel prosedur perhitungan nilai tambah metode Hayami pada Tabel 2. 
Tabel 2. Prosedur Perhitungan Nilai Tambah Metode Hayami

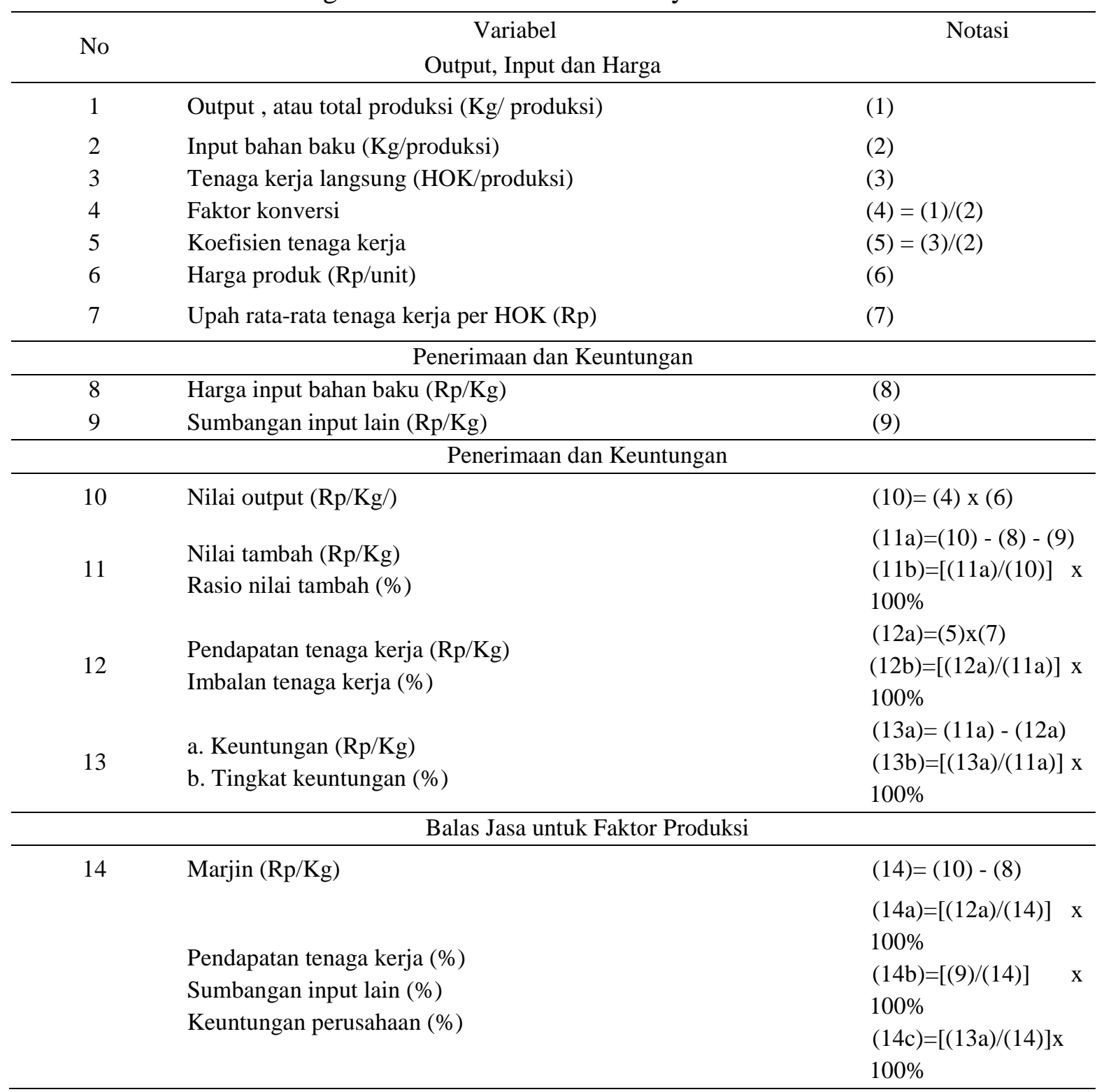

Berdasarkan pada hasil nilai tambah kemudian dapat dilihat pada kriteria pengambilan keputusan berikut yang mengacu pada Mumpuningsih (2008). Kriteria penilaian nilai tambah sebagai berikut:

1) Jika nilai tambah $>0$ berarti agroindustri dodol tomat memberikan nilai tambah (positif).

2) Jika nilai tambah $<0$ berarti agroindustri dodol tomat tidak memberikan nilai tambah (negatif).

Selain itu, pada penelitian juga dilakukan pengujian nilai tambah menurut kriteria pengujian Hubeis dalam Hermawatie, 1998 sebagai berikut :

Rasio nilai tambah rendah apabila memiliki persentase $<15$ persen

Rasio nilai tambah sedang apabila memiliki persentase $15-40$ persen

Rasio nilai tambah tinggi apabila memiliki persentase $>40$ persen

\section{HASIL DAN PEMBAHASAN}

Agroindustri dodol tomat merupakan agroindustri yang dikelola oleh Kelompok Wanita Tani Mentari di Desa Genteng, Kecamatan Sukasari, Kabupaten Sumedang. Agroindustri dodol tomat sudah berjalan sejak tahun 2017 dan saat ini jumlah anggota sebanyak 25 orang. Latar belakang dari pendirian agroindustri dodol tomat ini adalah keinginan untuk melakukan pengembangan dari pengolahan komoditas tomat yang jumlah 
produksinya melimpah di Desa Genteng. Ketersediaan bahan baku tomat dengan harga murah, memungkinkan KWT Mentari untuk melakukan usaha secara kontinyu serta melihat proses proses pembuatan atau pengolahannya yang sederhana.

Kemampuan perusahaan dalam menentukan produk utama yang akan diproduksi adalah hal penting yang akan menentukan tingkat biaya dan keuntungan yang akan diperoleh (Sari dan Putri, 2019). Perhitungan nilai tambah pada pengolahan dodol tomat dilakukan pada satu kali proses produksi yang berlangsung kurang lebih satu hari dengan waktu produksi yang dibutuhkan selama kurang lebih 2 jam. Dalam perhitungan tersebut terdapat beberapa komponen-komponen yang digunakan dalam perhitungan nilai tambah, antara lain yaitu output, input, tenaga kerja langsung, harga output, upah rata-rata tenaga kerja HOK, harga bahan baku, dan sumbangan input lain.

Seluruh komponen analisis diukur dan dinyatakan dalam satuan satu kilogram (1 kg) bahan baku. Hal ini dilakukan agar diketahui besarnya pertambahan nilai dari $1 \mathrm{~kg}$ bahan baku yang dibentuk oleh kegiatan pengolahan. Hasil nilai tambah dengan metode Hayami pada pengolahan dodol tomat pada agroindustri KWT Mentari dapat dilihat pada Tabel 3.

Tabel 3. Perhitungan Nilai Tambah Pada Agroindustri Dodol Tomat

\begin{tabular}{|c|c|c|}
\hline No & $\begin{array}{l}\text { Variabel } \\
\text { Output, Input dan Harga }\end{array}$ & Nilai \\
\hline 1 & Output / total produksi (kg/produksi) & 12 \\
\hline 2 & Input bahan baku (Kg/produksi) & 10 \\
\hline 3 & Tenaga kerja langsung (HOK/produksi) & 2 \\
\hline \multirow[t]{2}{*}{ No } & Variabel & Nilai \\
\hline & Output, Input dan Harga & \\
\hline 6 & Harga produk $(\mathrm{Rp} / \mathrm{Kg})$ & 25.000 \\
\hline 7 & Upah rata-rata tenaga kerja per HOK (Rp) & 20.000 \\
\hline \multicolumn{3}{|c|}{ Penerimaan dan Keuntungan } \\
\hline 8 & Harga input bahan baku $(\mathrm{Rp} / \mathrm{Kg})$ & 6.000 \\
\hline 9 & Sumbangan input lain $(\mathrm{Rp} / \mathrm{Kg})$ & 12.660 \\
\hline 10 & Nilai output $(\mathrm{Rp} / \mathrm{Kg} /)$ & 30.000 \\
\hline \multirow[t]{2}{*}{11} & Nilai tambah $(\mathrm{Rp} / \mathrm{Kg})$ & 11.340 \\
\hline & Rasio nilai tambah (\%) & $37,8 \%$ \\
\hline \multirow[t]{2}{*}{12} & Pendapatan tenaga kerja $(\mathrm{Rp} / \mathrm{Kg})$ & 4.000 \\
\hline & Imbalan tenaga kerja $(\%)$ & $35,27 \%$ \\
\hline \multirow[t]{2}{*}{13} & a. Keuntungan $(\mathrm{Rp} / \mathrm{Kg})$ & 7.340 \\
\hline & b. Tingkat keuntungan (\%) & $64,73 \%$ \\
\hline \multicolumn{3}{|c|}{ Balas Jasa untuk Faktor Produksi } \\
\hline \multirow[t]{4}{*}{14} & Marjin $(\mathrm{Rp} / \mathrm{Kg})$ & 24.000 \\
\hline & Pendapatan tenaga kerja (\%) & $16,67 \%$ \\
\hline & Sumbangan input lain (\%) & $52,75 \%$ \\
\hline & Keuntungan perusahaan (\%) & $30,58 \%$ \\
\hline
\end{tabular}

Berdasarkan Tabel 3. hasil perhitungan nilai tambah dengan metode Hayami diatas dalam satu kali proses produksi pengolahan dodol tomat KWT Mentari dapat mengolah bahan input yaitu tomat sebanyak 10 $\mathrm{kg}$ yang menghasilkan produk keluaran output berupa dodol tomat sebanyak $12 \mathrm{~kg}$. Pada setiap proses produksi dodol tomat dilakukan oleh 2 orang pekerja dengan upah harian HOK Rp. 20.000.

Faktor konversi merupakan pembagian antara output dengan input. Hasil penghitungan faktor konversi produk olahan dodol tomat yaitu sebesar 1,2. Nilai konversi tersebut berarti bahwa setiap satu kilogram tomat yang diolah menghasilkan dodol tomat sebesar 1,2 kilogram. Koefisien tenaga kerja 
diperoleh dari rasio antara jumlah hari kerja dengan bahan baku yang diolah. Hasil perhitungan diperoleh koefisien tenaga kerja sebesar 0,2 yang diartikan bahwa tenaga kerja dalam 1 hari kerja mampu mengolah bahan baku sebanyak $0,2 \mathrm{~kg}$.

Kemudian untuk harga output dari hasil pengolahan dodol tomat sebesar Rp. 25.000 per kg. Harga input atau bahan baku tomat yang digunakan dalam pengolahan dodol tomat berdasarkan kisaran harga ratarata tomat di Desa Genteng yaitu sebesar Rp. 6.000 per kg. Untuk satu kilogram bahan baku tomat menghasilkan sumbangan input lain sebesar Rp. 12.660.Nilai output merupakan hasil perkalian antara harga ouput dengan faktor konversi. Nilai output yang dihasilkan dari pengolahan dodol tomat sebesar Rp. 30.000. Artinya untuk setiap $1 \mathrm{~kg}$ bahan baku tomat yang diolah akan menghasilkan nilai output sebesar Rp. 30.000 .

Distribusi nilai tambah terhadap balas jasa atau pendapatan tenaga kerja langsung diperoleh dari perkalian antara koefisien tenaga kerja dengan upah rata-rata tenaga kerja. Balas jasa tenaga kerja menunjukkan jumlah pendapatan rata-rata yang diterima tenaga kerja untuk setiap kegiatan pengolahan dodol tomat yaitu sebesar Rp. 4.000 per kg bahan baku. Jadi, untuk setiap $1 \mathrm{~kg}$ dodol tomat tenaga kerja menghasilkan pendapatan sebesar Rp. 4.000.

Keuntungan merupakan selisih antara nilai tambah dengan pendapatan tenaga kerja langsung. Keuntungan yang diperoleh dari proses pengolahan dodol tomat adalah sebesar Rp. 7.340 per $\mathrm{kg}$. Keuntungan tersebut memiliki tingkat keuntungan sebesar $64,73 \%$ dari hasil pengolahan. Artinya dari satu kilogram pengolahan bahan baku tomat menguntungkan sebesar $64,73 \%$.

Nilai tambah merupakan pengurangan antara nilai output dengan harga bahan baku dan sumbangan input lainnya. Berdasarkan pengolahan satu kilogram tomat dan unsur-unsur sumbangan input lain menghasilkan nilai tambah sebesar Rp. 11.340 per $\mathrm{kg}$ bahan baku. Rasio nilai tambah merupakan perbandingan antara nilai tambah dengan nilai output dikalikan $100 \%$. Rasio nilai tambah dari proses pengolahan dodol tomat yaitu $37.8 \%$. Besarnya nilai tambah yang didapat dari perhitungan sejalan dengan besarnya rasio nilai tambah terhadap nilai output.

Setelah melakukan perhitungan nilai tambah, maka dilakukan pengujian menurut kriteria Hermawatie, 1998 sebagai berikut :

Rasio nilai tambah rendah apabila memiliki persentase $<15 \%$.

Rasio nilai tambah sedang apabila memiliki persentase $15 \%-40 \%$.

Rasio nilai tambah tinggi apabila memiliki persentase $>40 \%$.

Dengan demikian, berdasarkan kriteria diatas, maka dapat dikategorikan nilai tambah pada agroindustri olahan dodol tomat tergolong sedang, dimana besar persentase yang dihasilkan sebesar $37.8 \%$. Selanjutnya, nilai tambah yang diperoleh merupakan balas jasa untuk masing-masing faktor produksi yang digunakan.Oleh karena itu, untuk mengetahui besarnya balas jasa yang diberikan dari nilai tambah yang diperoleh, maka terlebih dahulu harus diketahui marjin antara nilai produk yang dihasilkan dengan bahan baku utama yang digunakan. Adapun besarnya marjin diperoleh dari perhitungan analisis nilai tambah pada usaha agroindustri pengolahan didistribusikan untuk sumbangan input lain 52,75\% merupakan bagian terbesar apabila dibandingkan dengan pendapatan tenaga kerja dan keuntungan produsen. Hal ini menunjukkan bahwa kegiatan produksi pengolahan dodol tomat membutuhkan input lain (bahan-bahan penunjang) yang relatif lebih banyak daripada kebutuhan bahan baku (tomat). Selanjutnya, distribusi marjin terkecil adalah pendapatan tenaga kerja (16,67\%) yang disebabkan oleh kondisi bahwa pada usaha pengolahan dodol tomat relatif menggunakan sedikit tenaga kerja dalam proses produksi.

\section{KESIMPULAN}

Berdasarkan hasil pembahasan maka dapat diambil kesimpulan sebagai berikut Nilai tambah (value added) yang diperoleh dari pengolahan dodol tomat oleh KWT Mentari bernilai positif yaitu sebesar Rp $11.340 / \mathrm{kg}$ dengan rasio nilai tambah 37.8 kategori sedang. 


\section{SARAN}

Berdasarkan hasil dari pembahasan serta dilihat dari kesimpulan, untuk pelaku usaha Agrondustri dodol tomat KWT Mentari disarankan dapat mengembangkan variasi dari produk olahan tomat lainnya, misalnya membuat selai tomat, manisan, yoghurt, sirup dan sebagainya yang tentunya akan meningkatkan nilai tambah dan pendapatan KWT Mentari.

\section{DAFTAR PUSTAKA}

Bantacut, T. (2013) 'Pembangunan Ketahanan Ekonomi dan Pangan Perdesaan Mandiri Berbasis Nilai Tambah', Jurnal Pangan, 22(2), pp. 397-406.

Dewi, Kurnia Harlina, Nusril, Helmiyetti, Yessi Rosalina, and P. S. (2015) 'Analisis Nilai Tambah Kopi Teripang Jahe Pra Campur Saset', Jurnal AGRISEP, 12(2), pp. 209-216. doi: 10.31186/jagrisep.12.2.209-216.

Dinar and Marina, I. (2018) 'SISTEM PERENCANAAN PRODUKSI PADA KOMODITAS TOMAT ( Lycopersicum esculentum Mill ) ( Lycopersicum esculentum Mill ) Produksi tomat Provinsi Jawa Barat berdasarkan Data Statistik Pertanian dan Perikanan Kabupaten Majalengka Tahun 2012-', 6.

Hayami, Yujiro, Toshihiko Kawagoe, Yoshinori Marooka, and Masdjidin, S. (1987) Agricultural Marketing and Processing in Upland Java A Perspective From A Sunda Village. Bogor: CGPRT Centre.

Hermawatie (1998) Agroindustri Tempe dan Peran Koperasi Dalam Pengembangannya. Universitas Brawijaya.

Iskandar (2009) Metode Penelitian Kualitatif. Jakarta (ID): Gaung persada (GP Press).

Mumpuningsih, G. (2008) 'Analisis Nilai Tambah dan PenerimaanAgroindustri Tiwul Instant di Malang Selatan', Jurnal Penelitian Pertanian Tropika, 16, pp. 88-98.

Purwadi , Agus, Widdi Ussada, dan I. (2007) 'Pengaruh Lama Waktu Ozonisasi Terhadap Umur Simpan Buah Tomat (Lycopersicum esculentum Mill)', in PERTEMUAN DAN PRESENTASI ILMIAH PENELITIAN DASAR ILMU PENGETAHUAN DAN TEKNOLOGI NUKLIR.

Ruauw, E. (2015) 'Analisis Keuntungan Dan Nilai Tambah Agriindustri Manisan Pala Ud Putri Di Kota Bitung’, Agri-Sosioekonomi, 8(1), p. 31. doi: 10.35791/agrsosek.8.1.2012.7359.

Sari, R. I. K. and Putri, M. A. (2019) 'Analisis Nilai Tambah Produk Olahan Ubi Kayu Di Kota Payakumbuh Analysis Of Value Added Wood Sweet Processed Products In Payakumbuh City', Journal of Food System and Agribusiness, 3(1), pp. 9-14.

Supriyati, dan E. S. (2016) 'Peranan, Peluang dan Kendala Pengembangan Agroindustri di Indonesia', Forum penelitian Agro Ekonomi, 24(2), p. 92. doi: 10.21082/fae.v24n2.2006.92-106. 